\title{
Non-Invasive Parameter Identification in Rotordynamics via Fluid Film Bearings: Linking Active Lubrication and Operational Modal Analysis
}

\author{
Santos, IImar; Svendsen, Peter Kjær
}

Published in:

Journal of Engineering for Gas Turbines and Power

Link to article, DOI:

$10.1115 / 1.4035447$

Publication date:

2017

Document Version

Peer reviewed version

Link back to DTU Orbit

Citation (APA):

Santos, I., \& Svendsen, P. K. (2017). Non-Invasive Parameter Identification in Rotordynamics via Fluid Film Bearings: Linking Active Lubrication and Operational Modal Analysis. Journal of Engineering for Gas Turbines and Power, 139, [ 062507]. https://doi.org/10.1115/1.4035447

\section{General rights}

Copyright and moral rights for the publications made accessible in the public portal are retained by the authors and/or other copyright owners and it is a condition of accessing publications that users recognise and abide by the legal requirements associated with these rights.

- Users may download and print one copy of any publication from the public portal for the purpose of private study or research.

- You may not further distribute the material or use it for any profit-making activity or commercial gain

- You may freely distribute the URL identifying the publication in the public portal 


\section{NON-INVASIVE PARAMETER IDENTIFICATION IN ROTORDYNAMICS VIA FLUID FILM BEARINGS - LINKING ACTIVE LUBRICATION AND OPERATIONAL MODAL ANALYSIS}

\author{
IImar Ferreira Santos* \\ Department of Mechanical Engineering \\ Technical University of Denmark \\ 2800 Kgs. Lyngby, Denmark \\ Email: ifs@mek.dtu.dk
}

\author{
Peter Kjær Svendsen \\ Department of Mechanical Engineering \\ Technical University of Denmark \\ 2800 Kgs. Lyngby, Denmark \\ Email: peter.kj.svendsen@gmail.com
}

\begin{abstract}
In recent years, theoretical and experimental efforts have transformed the conventional tilting-pad journal bearing (TPJB) into a smart mechatronic machine element. The application of electromechanical elements into rotating systems makes feasible the generation of controllable forces over the rotor as a function of a suitable control signal. The servovalve input signal and the radial injection pressure are the two main parameters responsible for dynamically modifying the journal oil film pressure and generating active fluid film forces in controllable fluid film bearings. Such fluid film forces, resulting from a strong coupling between hydrodynamic, hydrostatic and controllable lubrication regimes, can be used either to control or to excite rotor lateral vibrations. If non-invasive forces are generated via lubricant fluid film, in situ parameter identification can be carried out, enabling evaluation of the mechanical condition of the rotating machine.

Using the lubricant fluid film as a non-invasive calibrated shaker is troublesome, once several transfer functions among mechanical, hydraulic and electronic components become necessary. In this framework the main original contribution of this paper is to show experimentally that the knowledge about the several transfer functions can be bypassed by using output-only identification techniques. The manuscript links controllable (active) lubrication techniques with operational modal analysis, allowing for in-situ parameter identification in rotordynamics, i.e. estimation of damping ratio and natural frequencies.
\end{abstract}

The experimental analysis is carried out on a rigid rotorlevel system supported by one single pair of pads. The estimation of damping and natural frequencies is performed using classical experimental modal analysis (EMA) and operational modal analysis (OMA). Very good agreements between the two experimental approaches are found. Maximum values of the main input parameters, namely servovalve voltage and radial injection pressure, are experimentally found with the objective of defining ranges of non-invasive perturbation forces.

\section{INTRODUCTION}

Controllable fluid film bearings (CFFBs) are designed in a "synergistic relationship" to different types of electromechanical actuators [1-4]. For example, oil or water lubricated bearings are normally connected to servovalves and hydraulic servo systems [5-7], while gas or air lubricated bearings use piezoelectric actuators and pneumatic systems $[8-10]$. Direct and indirect types of control action onto the rotating shaft can be found. The control actuation influences four parameters: either the bearing gap function $h[11-14]$ and its geometry $d h / d \theta[15-17]$, or the fluid viscosity $\mu$ [18 19], or the fluid film pressure field $p[20-22]$. All four parameters are directly and explicitly written inside the Reynolds equation and significantly affect the static and dynamic interaction between rotating parts (journal) and stationary parts (bearing surface) of the machines. The possibility of actively controlling the behaviour of such parameters allows for engineering smart design solutions 
and significant performance improvements of the machines.

In the case of actively lubricated bearings (ALBs) - a special variant of CFFBs where the fluid film pressure field is controlled via servo-hydraulic or piezoelectric systems - the bearings are intentionally designed to be able to operate conventionally, i.e. under hydrodynamic and aerodynamic lubrication conditions; when enhancements of performance are desired, such goals are achieved by well-tuned feedback control laws [21,23]. Controllable fluid film bearing technology has a relatively short history of about two decades [5, -7, 12, 20]; it is in its infancy in comparison to the active magnetic bearing technology. The behaviour of CFFBs has been theoretically as well as experimentally investigated mostly under controlled laboratorial conditions, but slowly the technology is becoming mature towards industrial applications $[4,6,7,24,25]$. The majority of the results shown in the literature focus on vibration control [5.-7], enhancement of bearing damping properties [26], compensation of cross coupling effects [27], enlargement of stability range of rigid [21] and flexible rotors [24,27], and compensation of thermal effects [28, 31]. The idea of using controllable fluid film bearings as a "non-invasive calibrated shaker" to aid rotordynamic testing similar to the usage of active magnetic bearings [32,-36] - was first mentioned in [4], preliminarily exploited in [37] and more deeply investigated in [38]. In [38] the experimental characterization of the active fluid film forces were carried out in the frequency domain using a pair of actively lubricated tilting-pads. The application of ALBs as a calibrated shaker with the goal of determining the frequency response function (FRF in $\mathrm{m} / \mathrm{N}$ ) of a rotordynamic system was demonstrated. The supply pressure and servovalve input signal are two key parameters which significantly influence the rotor-journal bearing system dynamics. Indicators based on the amplitude of coherence functions were found and used to determine how small such "non-invasive" active fluid film forces should be to properly excite the rotor-journal bearing system without changing its static and dynamic characteristics. In terms of industrial and practical applications of ALBs as a non-invasive testing device it would be very useful to bypass the necessity of knowing precisely the transfer function between output (active fluid film force applied to the rotor) and input (servovalve input signal) in $\mathrm{N} / \mathrm{V}$ to use ALBs as a calibrated shaker to perform rotordynamic tests.

Operational modal analysis (OMA) are widely applied in the civil engineering area when modal parameter estimation of buildings and bridges is experimentally carried out due to the difficulty of exciting large structures such as buildings and bridges. In the past decade parameter identification procedures based solely on the system dynamic response have rapidly developed and found acceptance in several other areas of engineering, including mechanical engineering [39, 41]. Such techniques have never been used in connection with actively lubricated bearings.

In this framework, the original contribution of this work is to link active lubrication techniques to OMA aiming at performing rotordynamic tests and parameter identification via ALBs without using the information about the applied fluid film forces. The procedure is based only on the measurement of system response, i.e. rotor lateral movement. Random signal with small amplitude is though used as input to the servovalve. Consequently, small pressure and flow changes are generated, leading to non-invasive small fluid film forces. Non-invasive forces means forces able to perturb the rotor-bearing system via fluid film without significant changes to the original static equilibrium position of the journal and without altering the system dynamics. The original contribution of the work relies on a very extensive experimental campaign, focused on the identification of modal parameters such as damping ratio and natural frequency of a simple rotor-bearing system. EMA and OMA are consistently compared throughout the whole experimental campaign, using ALBs and a conventional electromagnetic shaker as excitation sources. The results obtained via the electromagnetic shaker are used as a benchmark to validate the performance of ALBs as a non-invasive shaker.

\section{TEST APPARATUS AND EXPERIMENTAL PROCE- DURES}

The experimental work is carried out by using the test apparatus illustrated in Fig. 1. The indicated dashed box in red contains the rotor-lever system under investigation. The operational principle of the rotor-lever system is schematized in Fig. 2. The two parallel arms $\mathbf{1 6}$ of the lever system and the rotor are considered as a single rigid body. The rotor is connected to the parallel arms by means of a pair of conical roller bearings, which are mounted inside the parallel arms at point $\mathrm{O}_{2}$. The rotor-lever system is pivoted at the extremity $O_{1}$ using two ball bearings. They constrain five of the six possible degrees of freedom of the rigid body and allow only rotational movements around point $O_{1}$. The whole system dynamics becomes restricted to a 2 dimensional problem, where forces are applied to the middle and free extremity of the arms via a pair of actively-lubricated tilting-pads and an electromagnetic shaker, respectively. The pair of tilting-pads inside of the bearing housing constrains the amplitude of the arm movements to very small angles. It means that small vertical displacements of the rotor center - positioned in the middle of the parallel arms - are assured. Static loads and electromagnetic dynamic forces are applied to the free extremity of the arm. It is important to highlight that tilting-pad bearings have an insignificant cross coupling effect between the vertical and horizontal directions. Operation principle of the test rig takes advantage of such a characteristic and all analyses are conducted in the vertical direction, without loss of generality.

Fig. 1 illustrates the whole electro-mechanical system. The driven system is composed of an AC motor and its frequency converter $\mathbf{1}$ controlled by a control unit $\mathbf{2}$. The torque is transmitted to the rotor by a belt. The rotor angular position and velocity are measured by means of a tachometer $\mathbf{3}$ installed directly 


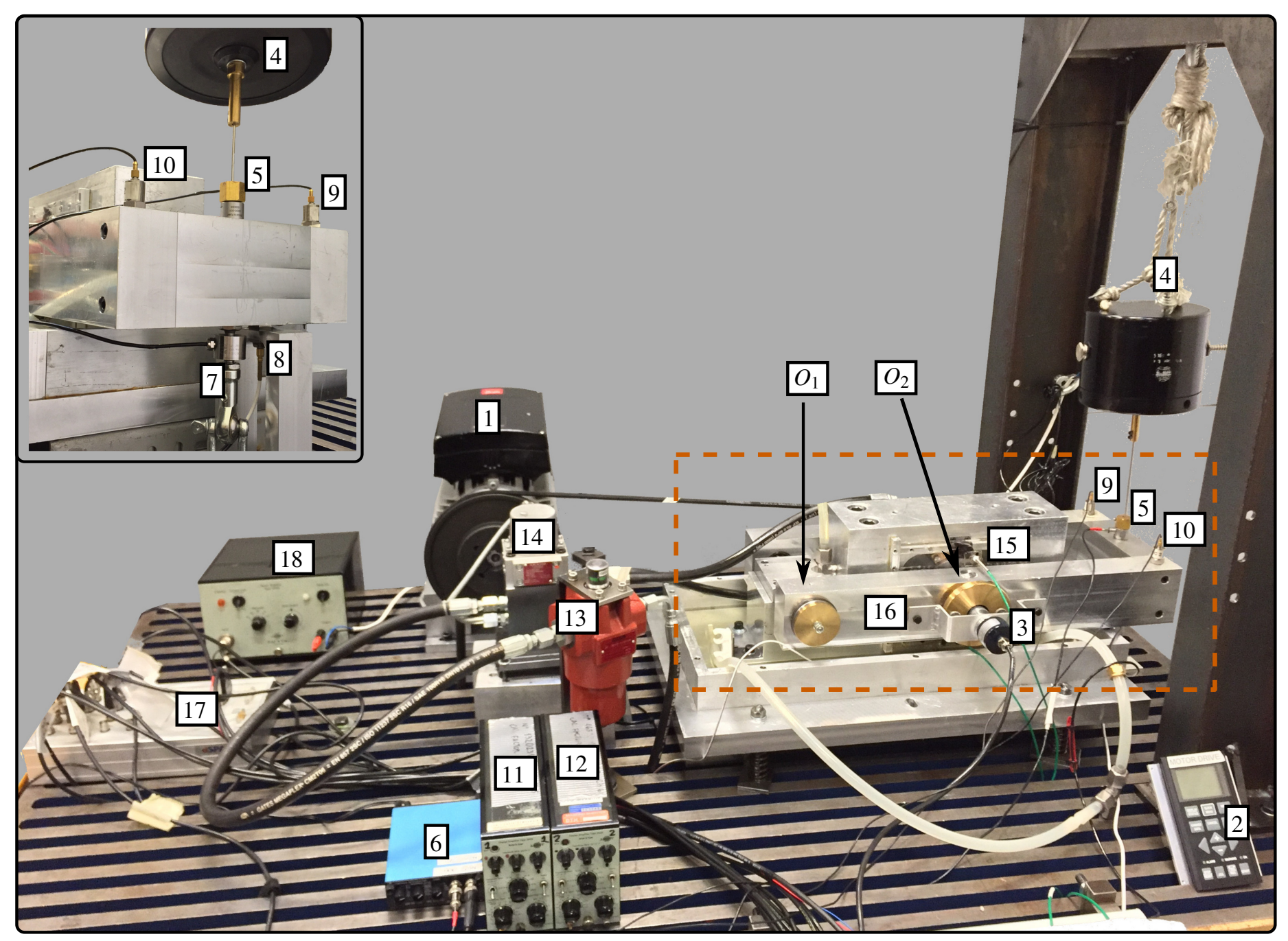

FIGURE 1: Photo of the test apparatus - the dashed box contains the rotor-lever system, which is schematized in Fig. 2 . The components of the test apparatus are: 1: AC motor and frequency converter, 2: Control unit for the frequency converter, 3: Tachometer, 4: Electromagnetic shaker, 5: Force transducer, 6: Amplifier for the force transducer, 7: Force transducer for the static load, 8: Displacment sensor, 9 and 10: Accelerometers, 11 and 12: Amplifiers for the accelerometers, 13: Oil filter, 14: Servovalve, 15: Pressure sensor (green wire), 16: Frame, 17: dSpace unit, 18: Amplifier for the electromagnetic shaker.

onto the rotor. Dynamic forces are applied to the arm extremity by means of the electromagnetic shaker 4 and measured by the force transducer 5 and its signal conditioner 6. Static loads are also applied to the arm extremity and are measured by the force transducer 7. The linear displacement sensor $\mathbf{8}$ detects the linear vertical movements of the arm extremity in the rotor-lever system middle plane. Two accelerometers $\mathbf{9}$ and $\mathbf{1 0}$ are attached to the free extremity of the arm and used to measure linear vertical accelerations of the arm extremity and verify that no undesired tilting movement outside of the plane of interest occurs. The acceleration signals are amplified by means of the signal conditioner 11 and 12. The fluid film forces are applied to the rotor- lever system in the middle of the arms. Oil pressure and flow are generated by a hydraulic unit not shown in the picture. The fluid lubricant flows through a filter $\mathbf{1 3}$ up to the high response servovalve 14. The servovalve is connected to the pair of tiltingpads by means of pipelines and is responsible for generating the active fluid film forces on top of the hydrodynamic forces. The controlled injection pressures in the pair of pads are measured by pressure sensors installed inside of the pads $\mathbf{1 5}$.

During the experimental campaign random as well as harmonic (chirp) signals are digitally generated on a PC computer (not shown in the picture), sent to the D/A card 17 to supply the power amplifier $\mathbf{1 8}$ of the electromagnetic shaker and the power 


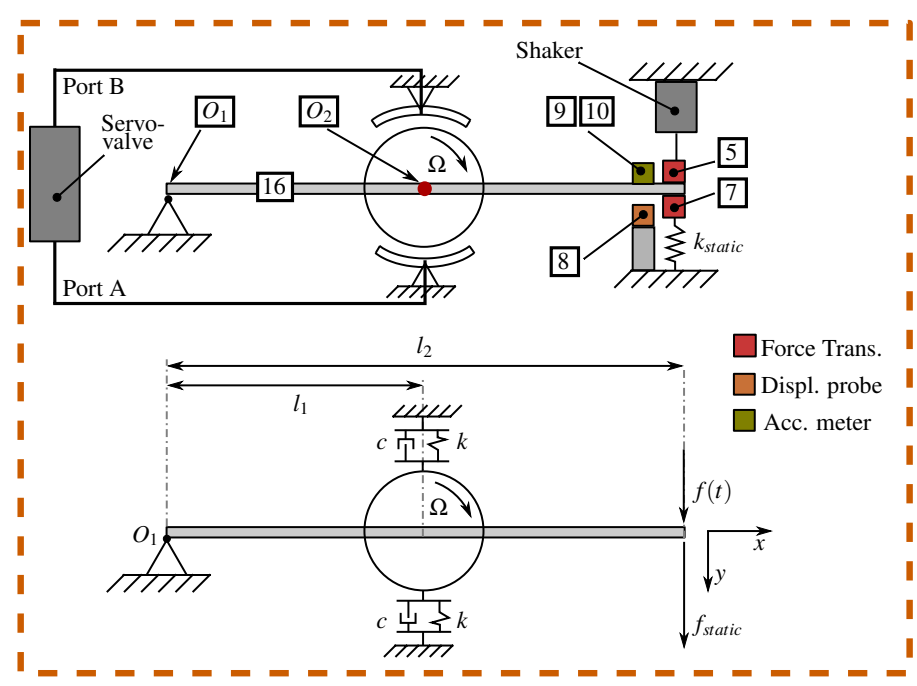

FIGURE 2. Schematic of the test rig operational principle and mechanical model.

amplifier of the servovalve (not shown in the picture). In order to ensure the performance of ALBs as a "non-invasive shaker" while performing rotordynamic tests, the results obtained by means of the actively-lubricated pair of pads are compared to the results obtained by using the electromagnetic shaker coupled to a force transducer. The results are summarized in the form of: i) frequency response functions (FRFs); ii) waterfall diagrams; iii) identified natural frequency; and iv) identified damping ratio. The results i) to iv) are obtained when static load, rotor angular velocity, injection pressure and amplitude of servovalve input signal are varied. Damping ratio and natural frequency are identified aided by classical EMA and OMA methods.

EMA and its algorithms for extracting modal parameters are discussed throughout the literature [42]. Such algorithms have their foundation in the knowledge of input (force) as well as output (displacement or acceleration) signals, while OMA uses only output signals. The Ibrahim time domain (ITD) algorithm introduced by Ibrahim and Mikulcik [43] in 1977 is one of the first algorithms developed for parameter estimation using multiple outputs. A closely related algorithm is the eigensystem realization algorithm (ERA) developed by Pappa et al. [44] and introduced in 1985. The estimation of modal parameters based on OMA algorithms demands computational power, and the rapid development of computers stimulated the development of many new algorithms in the nineties. One example is the stochastic subspace identification (SSI) algorithm developed in this period. SSI has gained acceptance since being formally introduced by Overschee and Moor [45]. The SSI identification technique is well known mainly because of its implementation in commercial software such as ARTeMIS. Brincker et al. [46] also made a significant contribution to the development of OMA by introducing the frequency domain decomposition (FDD) algorithm.
Many other algorithms are still being developed. In this work, however, the algorithms ITD, SSI and FDD are used. During the past decade such algorithms have been thoroughly validated, numerically as well as experimentally.

For all measurements an acquisition frequency of $f_{s}=$ $2000 \mathrm{~Hz}$ is utilized. In order to ensure robust estimates of the modal parameters the tests are performed using time intervals of $200 \mathrm{~s}$. All three response signals (two accelerations and one displacement) are used as an input to the OMA algorithms. The correlation function is calculated and a triangular-flat-top window is applied in order to stabilise the ITD algorithm, which is correlation-driven. The ITD algorithm identifies as many modal parameters as signals sent to the algorithm. Consequently, with three response signals used, three natural frequencies, damping ratios, and mode shapes are identified. In the frequency range of interest $(50-200 \mathrm{~Hz})$ only one pronounced natural frequency is observed. Evidently, the ITD algorithm has an oversized model of order two. The data-driven SSI technique is employed, i.e. the response is fed directly into the algorithm. Based on a stabilisation diagram, which shows the modal order, the SSI algorithm has been found to give good estimates with an oversized model of order two. An oversizing is needed because the ITD and the SSI algorithms do not include any noise modelling. The need of an oversized model is especially important in the presence of harmonic components (residual unbalance response). The spectral density function is calculated with Welch averaging, 50\% of overlap and a Hanning window. The spectral density function is arranged in a 3D matrix which is fed into the FDD algorithm. The FDD algorithm transforms the spectral density function into singular values, which are then plotted. The natural frequencies of the system can be identified by means of the singular value plot. An amplification of singular values indicates a natural frequency. A frequency band around the selected natural frequency is inverse Fourier transformed, and consequently, one obtains a free decay which is fed into the ITD algorithm. The combination of the FDD algorithm with a time domain technique allows for damping estimates and enhancement of the natural frequency estimates.

Table 1 reports the main dimensions and geometrical properties of the rotor-bearing system investigated, followed by the lubricant type used.

\section{ROTOR-BEARING SYSTEM UNDER CONVENTIONAL HYDRODYNAMIC LUBRICATION}

The rotor-lever system operates initially under conventional hydrodynamic lubrication. Seventeen angular velocities between 0 and $4,800 \mathrm{rpm}(80 \mathrm{~Hz})$ and three different load conditions are used: i) $200 \mathrm{~N}(0.034 \mathrm{MPa})$; ii) $1400 \mathrm{~N}(0.24 \mathrm{MPa})$; and iii) $2800 \mathrm{~N}(0.48 \mathrm{MPa})$. For sake of briefness only experimental results (FRFs) under conditions ii) and iii) are presented in Figs. $3 \mathrm{a}$ and $3 \mathrm{~b}$. The electromagnetic shaker imposes dynamic pertur- 


\begin{tabular}{lcc}
\hline Pad inner radius & 49.923 & $\mathrm{~mm}$ \\
Journal radius & 49.692 & $\mathrm{~mm}$ \\
Bearing axial length & 100 & $\mathrm{~mm}$ \\
Preload factor & 0.75 & - \\
Number of pads & 2 & - \\
Pad arc & 69 & $\mathrm{deg}$ \\
Offset & 0.5 & - \\
Load Angle & on pad & - \\
Pad thickness & 12 & $\mathrm{~mm}$ \\
Injection nozzle radius & 3 & $\mathrm{~mm}$ \\
Injection nozzle length & 10 & $\mathrm{~mm}$ \\
Oil type & ISO VG22 & - \\
Pad material & Brass & - \\
Pivot insert material & Steel & - \\
Oil temperature & $35 \sim 40$ & Celsius \\
\hline
\end{tabular}

TABLE 1: Test rig parameters and dimensions

bation forces in the frequency range $30-300 \mathrm{~Hz}$. The illustration of FRFs is shortened in the frequency range of interest, namely between 50 and $200 \mathrm{~Hz}$. The perturbation forces (input) are measured by the force transducer $\mathbf{5}$ and the vertical displacement of the rotor is measured by the displacement sensor $\mathbf{8}$ (see Fig. 1).

At zero angular velocity and no fluid film formation the pad pivot stiffness and the rotor-lever inertia define the system resonance frequency around $130 \mathrm{~Hz}$. The friction between the system components defines the level of damping. By increasing the rotor angular velocity from 0 to $2,400 \mathrm{rpm}(40 \mathrm{~Hz})$ the lubricant film between rotor and pads is formed and a significant amount of damping is introduced via hydrodynamic lubrication. This claim is easily confirmed by analysing the reduction of the resonance peaks around $130 \mathrm{~Hz}$ in the range from 0 to $2,400 \mathrm{rpm}(40 \mathrm{~Hz})$. By further increasing the rotor angular velocity from $2,400 \mathrm{rpm}$ $(40 \mathrm{~Hz})$ to $4,800 \mathrm{rpm}(80 \mathrm{~Hz})$ a significant reduction of damping is seen, as expected and predicted by the hydrodynamic theory. Comparing the two waterfall diagrams illustrated in Figs. 3a and $3 \mathrm{~b}$ one might conclude that the damping ratios in case ii) are slightly higher than in case iii).

Figs. 4 and 5 illustrate the behaviour of the two identified parameters, i.e. natural frequency and damping ratio, as a function of the angular velocity for the two load cases ii) and iii), respectively. The identification procedure is carried out using five approaches: a) EMA coupled to least squares algorithm; b) OMA aided by ITD algorithm; c) OMA aided by SSI algorithm; d) OMA aided by FDD algorithm; and e) mean values composed of all four values. In case a) force and displacement signals are used for the parameter identification while in cases b), c) and d) only the three output signals (one displacement and two acceleration) are used. Comparing Fig. 4a and Fig. 5a the reduction of the systems natural frequency as a function of the angular velocity can be seen. In case ii) the natural frequency varies from

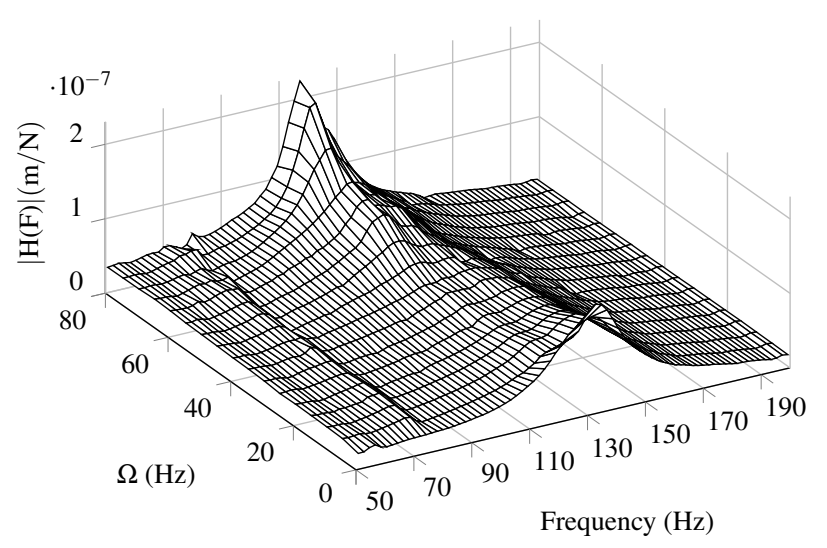

(a) Static load of $1400 \mathrm{~N}(0.24 \mathrm{MPa})$.

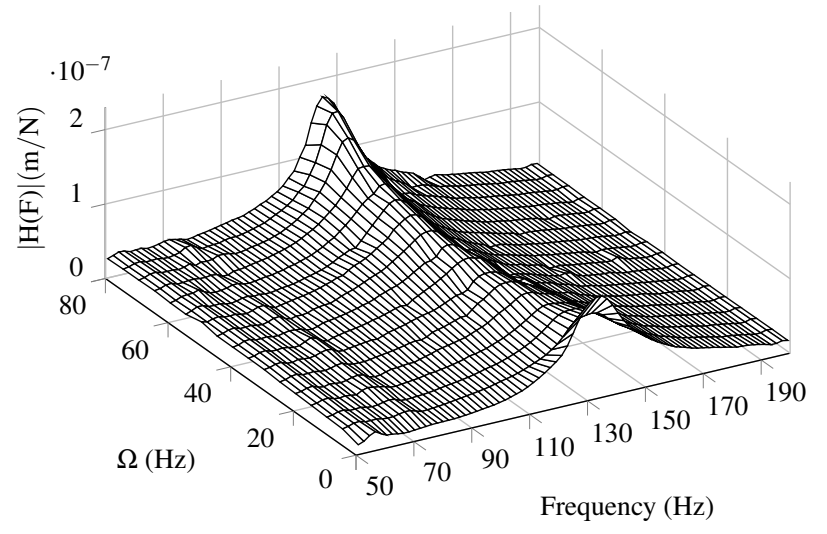

(b) Static load of $2800 \mathrm{~N}(0.48 \mathrm{MPa})$.

FIGURE 3: Experimental FRFs in $(\mathrm{m} / \mathrm{N})$ as a function of the rotor angular velocity and static load conditions: a) static load of $1400 \mathrm{~N}(0.24 \mathrm{MPa})$; b) static load of $2800 \mathrm{~N}$ (0.48 MPa).

$132 \mathrm{~Hz}$ at very low speeds to $119 \mathrm{~Hz}$ at $4,800 \mathrm{rpm}(80 \mathrm{~Hz})$. In case iii) it varies from $138 \mathrm{~Hz}$ at very low speeds to $128 \mathrm{~Hz}$, a more narrow range in comparison with case ii). Figs. $4 b$ and $5 b$ depict the behaviour of the damping ratio as a function of the rotor angular velocity for load cases ii) and iii). For load cases ii) and iii) maximum damping ratio values of 0.15 and 0.125 are achieved at 2,400 rpm $(40 \mathrm{~Hz})$ and $1,800 \mathrm{rpm}(30 \mathrm{~Hz})$, respectively. Good correspondence to the amplitudes of waterfall diagrams in Fig. $3 \mathrm{a}$ and $3 \mathrm{~b}$ are found, i.e. exactly at such angular velocities the rotor-lever system has its minimum vibration amplitudes. All algorithms based on EMA as well as on OMA identify the same behaviour for damping ratios as well as for natural frequencies. The identified damping ratios for case ii) are slightly higher than for case iii). For higher loads such as in case iii), the rotor-lever system dynamics is more strongly influenced by the pivot stiffness and it explains the slight reduction of damping ratio values for this case in comparison to case ii). The identified parameters presented in Figs. 4 and 5 will be used as benchmark to validate the same parameters obtained via ALBs 
as a non-invasive shaker in the next sections.

\section{ROTOR-BEARING SYSTEM UNDER CONTROLLABLE LUBRICATION}

When the hydrostatic and the hydrodynamic lubrication are simultaneously combined in a fluid film bearing, one refers to the hybrid lubrication. While the hydrodynamic lubrication regime is fundamentally driven by the journal angular velocity, the hydrostatic lubrication regime is driven by an external source of pressurization, i.e. a high pressure pump. Orifices and pockets are normally machined over the bearing surface and directly connected to the high pressure unit by means of pipelines. The pair of orifices is circumferentially machined around the bearing surface, normally 180 degrees from each other. Through the orifices the pressurized lubricant reaches the bearing gap, influences the lubricant film pressure responsible for the separation of the rotating surface from the stationary one, and carries the journal loads.

When part of the hydrostatic pressure is dynamically modified by means of hydraulic servo systems, one refers to the controllable lubrication. Such a lubrication regime is realized by further including a servovalve between the high pressure unit and a pair of orifices. Through the servovalve's input signal the lubricant pressure and flow through the pair of orifices are electronically modified, generating controllable lubricant film pres-

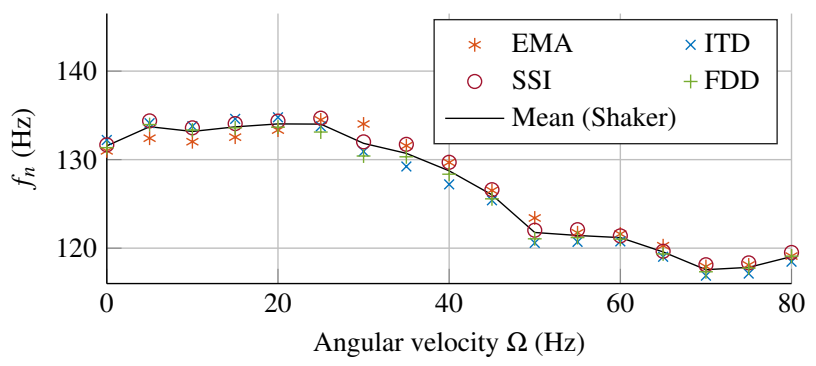

(a)

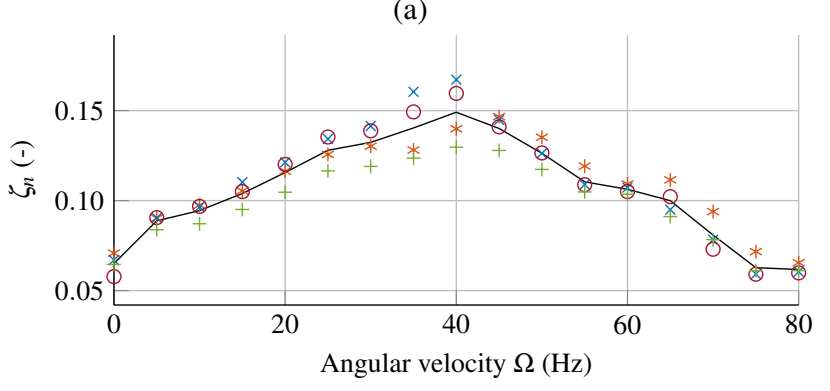

(b)

FIGURE 4: Experimental behaviour of the natural frequency and damping ratio as a function of the rotor angular velocity estimated via EMA (least squares algorithm) and OMA (ITD, SSI and FDD algorithms). Static load condition: $1400 \mathrm{~N}$ (0.24 MPa). Dynamic perturbation: electromagnetic shaker.

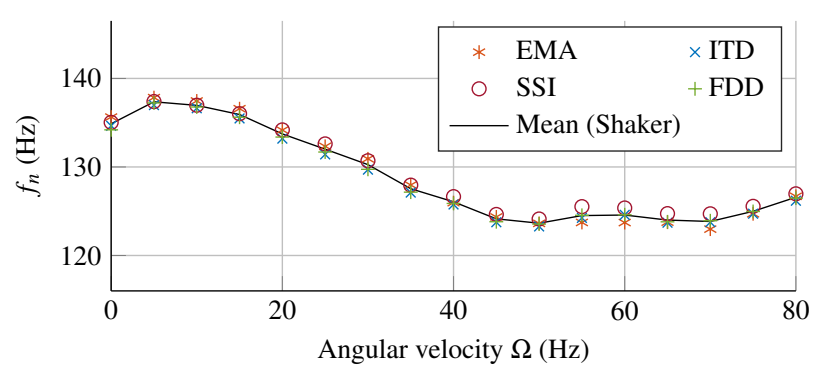

(a)

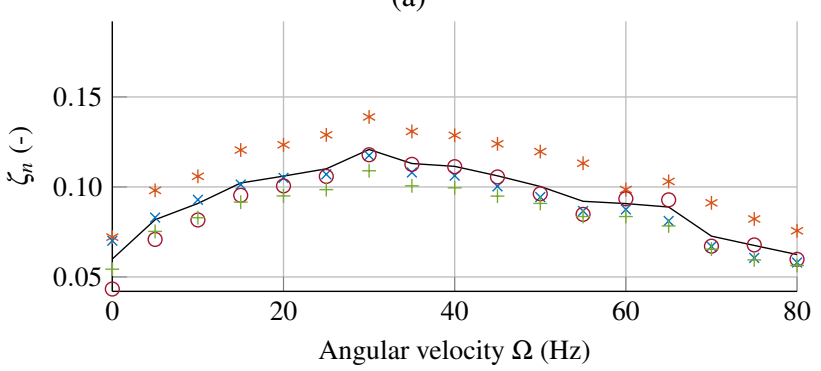

(b)

FIGURE 5: Experimental behaviour of the natural frequency and damping ratio as a function of the rotor angular velocity estimated via EMA (least square algorithm) and OMA (ITD, SSI and FDD algorithms). Static load condition: $2800 \mathrm{~N}$ (0.48 MPa). Dynamic perturbation: electromagnetic shaker.

sures and hence controllable forces. The controllable lubrication is regulated by a predefined input signal sent to the servovalve, which might not utilize any kind of feedback signal. When displacement sensors are installed in order to detect the lateral movements of the journal and their signals are used to build a feedback control law for the servovalve input signal, one refers to the active lubrication.

The rotor-lever system operates now under the controllable lubrication regime, i.e. the hydrodynamic plus the hydrostatic plus the controllable time-variant injection. Seventeen angular velocities between 0 and $4,800 \mathrm{rpm}(80 \mathrm{~Hz})$ and three different load conditions are used: i) $200 \mathrm{~N}(0.034 \mathrm{MPa})$; ii) $1400 \mathrm{~N}$ $(0.24 \mathrm{MPa})$; and iii) $2800 \mathrm{~N}(0.48 \mathrm{MPa})$. Once again, for sake of brevity only experimental results (FRFs) under conditions ii) and iii) are presented in Figs. 6a and 6b. The servovalve is fed by a chirp input signal with maximum amplitude of $0.17 \mathrm{~V}$ and a supply pressure of 15 bar (1.5 MPa), imposing dynamic fluid film perturbation forces in the frequency range between 30 to $300 \mathrm{~Hz}$. The illustration of FRFs is shortened in the frequency range of interest, namely between 50 and $200 \mathrm{~Hz}$ and obtained using the pressure sensor signal $\mathbf{1 5}$ as an input signal and the displacement sensor signal $\mathbf{8}$ as an output signal (see Fig. 11). It is important to highlight that Figs. $6 \mathrm{a}$ and $6 \mathrm{~b}$ should be compared to Figs. 3a and 3b with care. A direct quantitative comparison between Fig. 6 and Fig. 3 is not straightforward, once the lo- 
cation of the excitations and the FRF units in $\mathrm{m} / \mathrm{N}$ and $\mathrm{m} / \mathrm{bar}$ are different. Nevertheless, comparing them qualitatively, the vibration amplification around the resonance range of $130 \mathrm{~Hz}$ is clearly seen along the whole angular velocity range. Generally speaking, the rotor-lever system under hybrid lubrication conditions is slightly more damped than its conventionally lubricated counterpart.

Figs. 7 and 8 illustrate the behaviour of the two identified parameters, i.e. natural frequency and damping ratio, as a function of the angular velocity for the two load cases ii) and iii), respectively. The identification procedure is carried out using four approaches: a) EMA (FRF in ( $\mathrm{m} / \mathrm{bar}$ ) coupled to least squares algorithm; b) OMA aided by ITD algorithm; c) OMA aided by SSI algorithm; and d) OMA aided by FDD algorithm. The mean values obtained when the electromagnetic shaker perturbs the rotor-lever system, is plotted and used as a benchmark. In case a) pressure and displacement signals are used for the parameter identification while in cases b), c) and d) only the three output

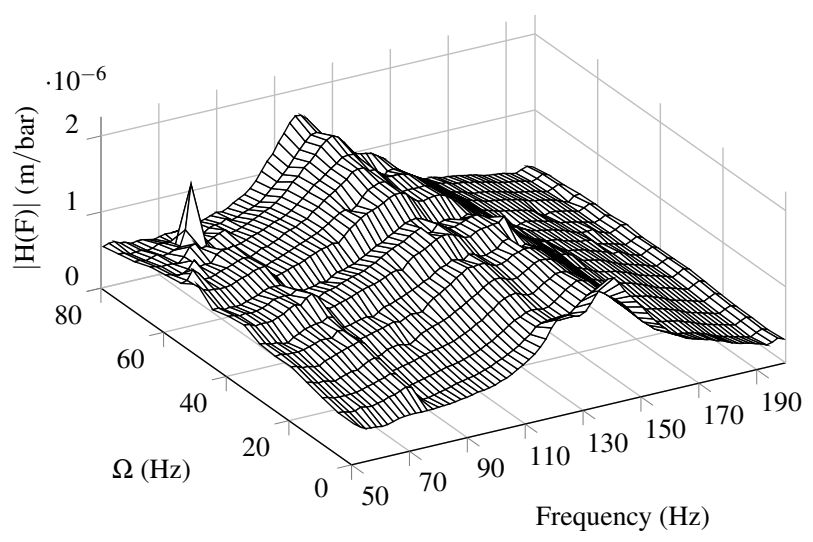

(a) Static load of $1400 \mathrm{~N}(0.24 \mathrm{MPa})$

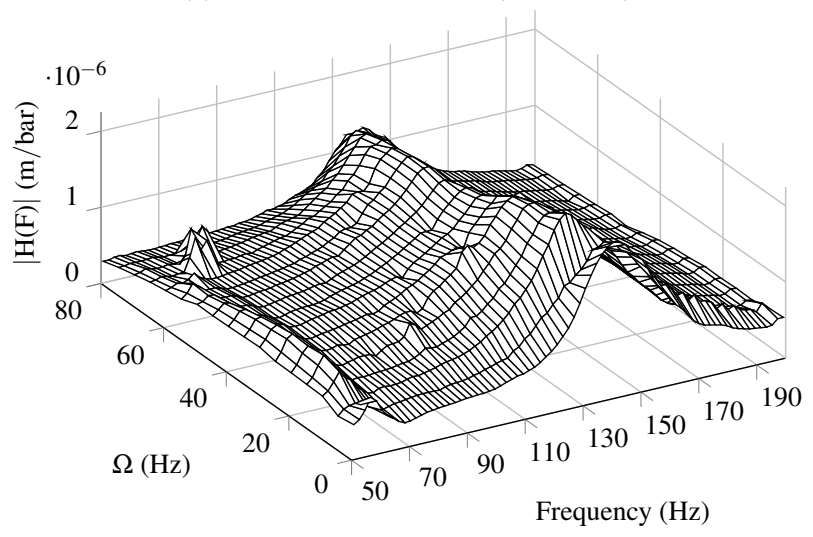

(b) Static load of $2800 \mathrm{~N}(0.48 \mathrm{MPa})$

FIGURE 6: Experimental FRFs in ( $\mathrm{m} /$ bar) as a function of the rotor angular velocity and static load conditions: a) static load of $1400 \mathrm{~N}$ (0.24 MPa); b) static load of $2800 \mathrm{~N}$ (0.48 MPa). signals (one displacement and two acceleration) are used. When comparing Fig. $7 \mathrm{a}$ and Fig. $8 \mathrm{a}$ the reduction of the systems natural frequency as a function of the angular velocity can be seen. In case ii) the natural frequency varies from $140 \mathrm{~Hz}$ at very low speeds to $120 \mathrm{~Hz}$ at $4,800 \mathrm{rpm}(80 \mathrm{~Hz})$. In case iii) it varies from $145 \mathrm{~Hz}$ at very low speeds to $130 \mathrm{~Hz}$ at $3,600 \mathrm{rpm}(60 \mathrm{~Hz})$, a more narrow range in comparison to case ii). Comparing the identified natural frequency values using the electromagnetic shaker and the ALB a clear correspondence is seen, especially for the case ii). Increasing the static loading, i.e. case iii), deviations are found, especially for the rotor angular velocities higher than $1,200 \mathrm{rpm}(20 \mathrm{~Hz})$. Nevertheless, the natural frequency trends are the same. All algorithms based on EMA as well as on OMA identify the same behaviour for the natural frequency.

Figs. $7 \mathrm{~b}$ and $8 \mathrm{~b}$ depict the behaviour of the damping ratio as a function of the rotor angular velocity for cases ii) and iii), respectively. For load cases ii) and iii) maximum damping ratio values around 0.175 and 0.135 are achieved at 2,400 rpm $(40 \mathrm{~Hz})$ and 1,800 rpm $(30 \mathrm{~Hz})$, respectively. All algorithms based on EMA as well as on OMA identify the same behaviour for the damping ratios. The identified damping ratios for case ii) are slightly higher than for case iii), as expected. As mentioned before, for higher loads the rotor-lever system dynamics are more strongly influenced by the pivot stiffness leading to a slight reduction of damping ratio values. Such a trend is seen when the electromagnetic shaker (continuous line) as well as the ALB is used as excitation devices.

\section{ELECTROMAGNETIC SHAKER vs ALB - PARAMETER STUDY AND STATISTICAL COMPARISON}

An extensive experimental campaign of 51 dynamic tests with the electromagnetic shaker, i.e. three static loading conditions at 17 rotor angular velocities, is carried out. Based on this campaign the mean values and $95 \%$ confidence intervals for the natural frequency and damping ratio are calculated, aided by the four different estimation algorithms based on EMA and OMA. The results are fitted using quadratic functions and presented in Fig. 9. The test campaign focuses on the effect of the hydrodynamic lubrication on the system dynamics. Generally speaking, the system damping ratio achieves its maximum value for static loads around $1500 \mathrm{~N}$ and angular velocities around 2,400 rpm $(40 \mathrm{~Hz})$. The systems natural frequency increases as a function of the static loading and decreases as the rotor angular velocity increases. The behaviour of the parameter mean values as a function of static load and rotor angular velocity are used as a benchmark.

Based on another extensive experimental campaign of 51 dynamic tests with the ALB as a shaker, the mean values and 95\% confidence intervals for the natural frequency and damping ratio are calculated, aided by the four different estimation algorithms based on EMA and OMA. The results are also fit- 


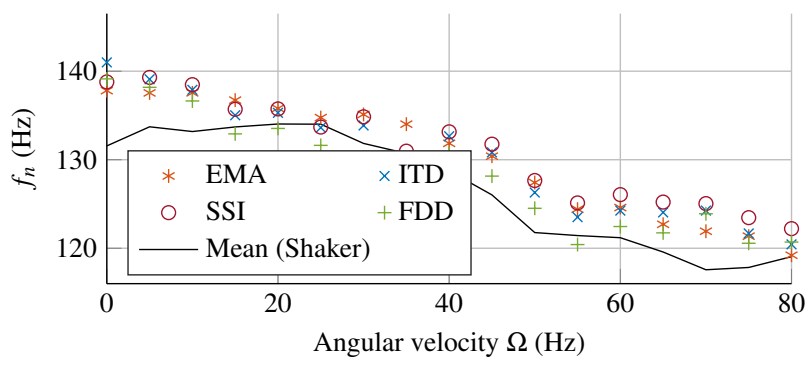

(a)

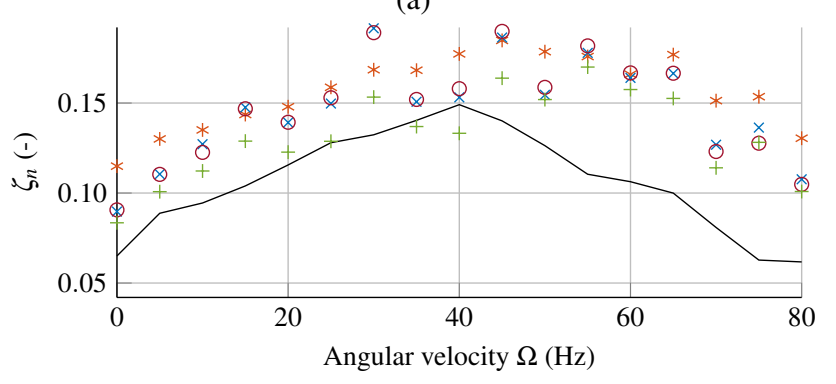

(b)

FIGURE 7: Experimental behaviour of the natural frequency and damping ratio as a function of the rotor angular velocity estimated via EMA (least square algorithm) and OMA (ITD, SSI and FDD algorithms). Static load condition: $1400 \mathrm{~N}$ (0.24 MPa). Dynamic perturbation: ALB as an actuator.

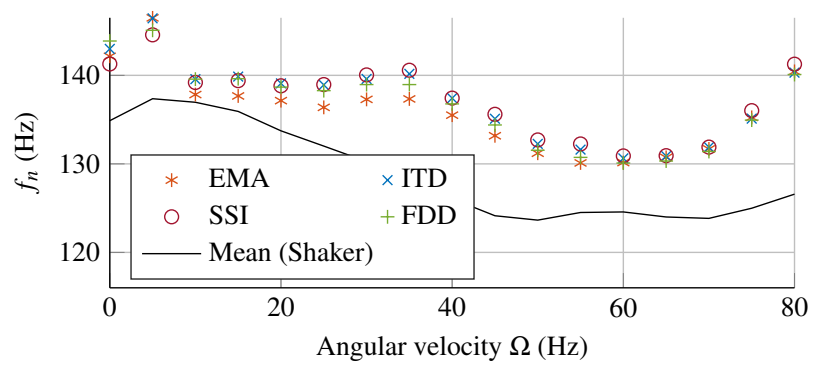

(a)

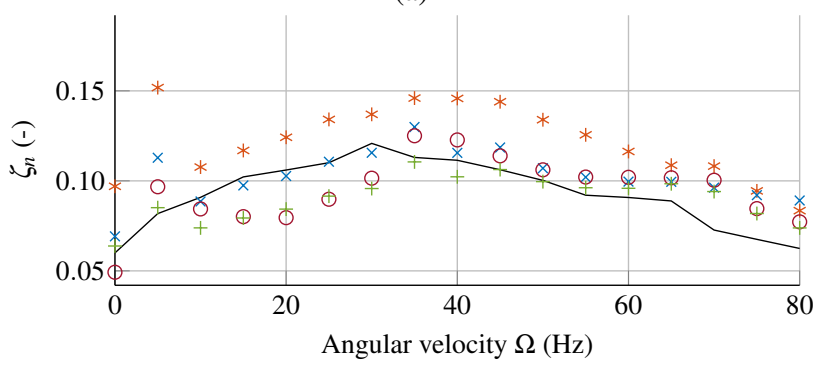

(b)

FIGURE 8: Experimental behaviour of the natural frequency and damping ratio as a function of the rotor angular velocity estimated via EMA (least square algorithm) and OMA (ITD, SSI and FDD algorithms). Static load condition: $2800 \mathrm{~N}$ (0.48 MPa). Dynamic perturbation: ALB as an actuator.
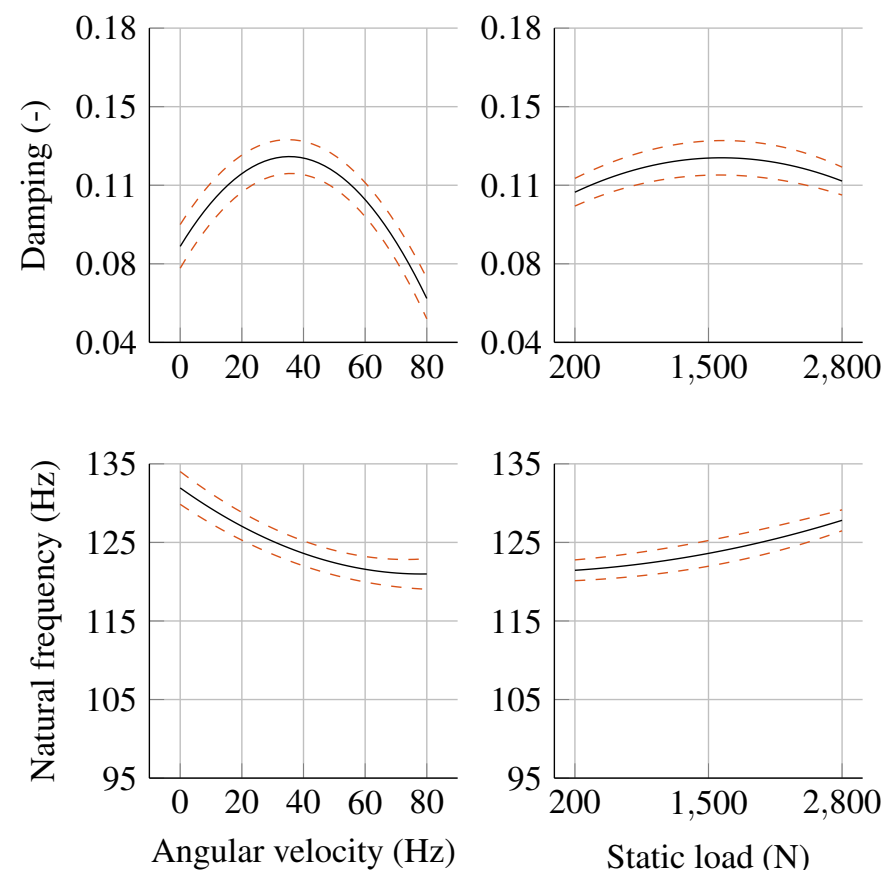

FIGURE 9: Curve-fitted mean values of damping ratio and natural frequency with $95 \%$ confidence interval as a function of the rotor angular velocity and static load. Dynamic perturbation: electromagnetic shaker.

ted using quadratic functions and presented in Fig. 10 . The behaviour of the modal parameters' mean values as a function of static load and rotor angular velocity follows benchmark values very well. When the controllable lubrication system is turned on, the dynamics of the original rotor-lever system slightly changes towards a more damped system. Generally speaking, the system damping ratio achieves its maximum value for static loads around $2000 \mathrm{~N}$ instead of $1500 \mathrm{~N}$ and angular velocities around $2,700 \mathrm{rpm}(45 \mathrm{~Hz})$ instead of $2,400 \mathrm{rpm}(40 \mathrm{~Hz})$. Its maximum mean value obtained that is aided by the ALB is approx. 0.14, a relatively small variation when compared to the value of $0.12 \mathrm{ob}-$ tained with the help of the electromagnetic shaker (Fig. 9). The systems natural frequency increases as a function of the static loading and decreases as the rotor angular velocity increases, the same trend obtained when the electromagnetic shaker is used. Aided by the ALB the natural frequency mean value is found at $115 \mathrm{~Hz}$ while with the electromagnetic shaker it is $123 \mathrm{~Hz}$. Coherence functions obtained with the help of the pressure sensor inside of the pads (element 15) and the displacement sensor (element 8) are also presented for all 51 dynamic tests. The high values of coherence, i.e. around 0.96, enssure the quality of the measurement campaign.

The non-invasive perturbation forces generated by the ALB are strongly dependent on two main parameters: the oil pressure supply $\left(p_{s}\right)$ and the amplitude of the input signal sent to the ser- 

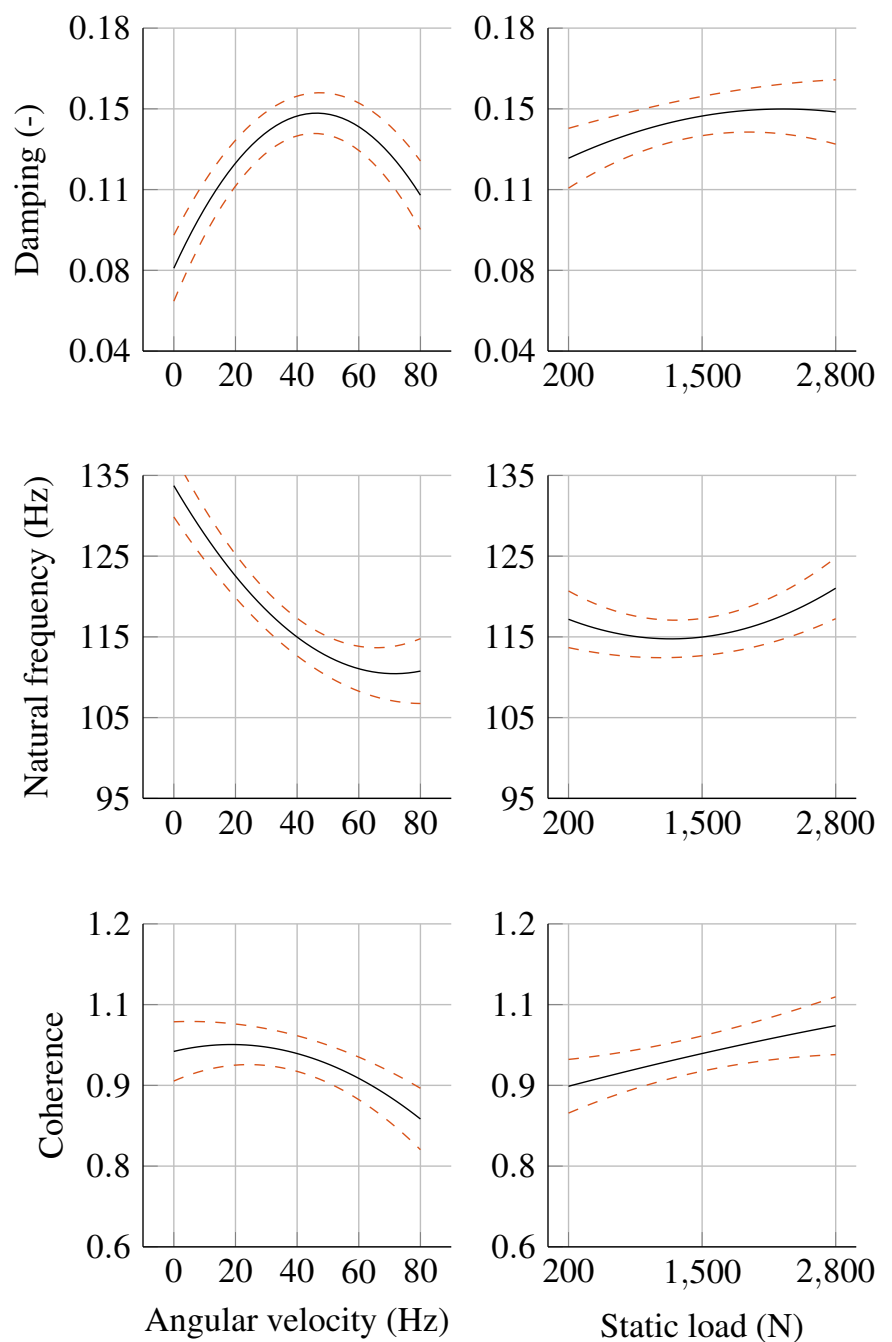

FIGURE 10: Curve-fitted mean values of damping ratio, natural frequency, and coherence with $95 \%$ confidence interval as a function of the rotor angular velocity and static load. Dynamic perturbation: ALB as an actuator.

vovalve. The input signal can be built by a constant value (DC) added by an alternating value (AC). With the DC value the static position of the servovalve piston is controlled, changing the pressure and flow through ports A and B (see Fig. 2) and allowing higher pressure and flow to one pad than to the other. In case of generation of non-invasive perturbation forces, i.e. forces which do not change the static equilibrium position of the journal, the DC value can be advantageously exploited. The DC value can be adjusted to reduce the injection of pressurized oil between the rotor and lower pad, which bears the static load, avoiding in this matter significant changes of the systems static equilibrium position. As a consequence of the adjustment of the DC value, the fluid film force between rotor and upper pad will be more significantly affected by the high injection pressure. The fluid film forces between rotor and upper pad become the main source of perturbation. On top of the DC value, the AC value of the input signal (random or chirp) can be added and varied with the aim of shaking the rotor-level system without altering its dynamics. Fig. 11 illustrates the influence of the three operational parameters, namely supply pressure $p_{s}, \mathrm{DC}$ and $\mathrm{AC}$ values of the input signal, on the identification of damping ratio and natural frequency. The results are obtained based on an exhaustive experimental campaign of over 50 tests using both EMA and OMA. The experimental campaign is carefully designed to achieve 95\% confidence using the software JMP and statistical tools for design of experiments [47]. Three values of static load (200 N, $1500 \mathrm{~N}$ and $2800 \mathrm{~N}), 3$ angular velocities $(0,2,400 \mathrm{rpm}$ and 4,800 rpm), 4 values of supply pressure ( 5 bar, 10 bar, 25 bar and 50 bar), 4 $\mathrm{DC}(-0.45 \mathrm{~V},-0.2 \mathrm{~V}, 0.2 \mathrm{~V}$ and $0.45 \mathrm{~V})$ and $5 \mathrm{AC}$ values $(0.1 \mathrm{~V}$, $0.2 \mathrm{~V}, 0.4 \mathrm{~V}, 0.6 \mathrm{~V}$ and $0.8 \mathrm{~V}$ ) are used. The mean values of the coherence function are also documented in Fig. 11 for all three study cases to ensure the quality of the experimental campaign. Fig. 11 is obtained when the rotor angular velocity is $2,400 \mathrm{rpm}$ $(40 \mathrm{~Hz})$ and the static load is $1500 \mathrm{~N}$, i.e. the central values of static load and angular velocity ranges (see Fig. 10,

As mentioned previously, the rotor-lever system under hybrid lubrication conditions is slightly more damped than its counterpart conventionally lubricated. It means that the lower the damping ratio identified via ALB the closer one might be to the dynamics of the original system conventionally lubricated. Generally speaking, the application of ALB as a shaker leads to a slight underestimation of natural frequencies, especially at high angular velocities. With this information in mind, Fig. 11 can be analysed:

- Influence of supply pressure - It can be inferred that low values of supply pressure lead to slight overestimation of damping ratio followed by a significant reduction in coherence. Optimal values of supply pressure $p_{s}$ seem to exist around $25 \mathrm{bar}$, where the mean values of identified damping ratio is 0.14 and of the identified natural frequency $114 \mathrm{~Hz}$. It is worth mentioning the high value of coherence, i.e. 0.96 , for such a value of supply pressure.

- Influence of servovalve input signal (DC Values) Analysing the influence of the DC values on the identification of the modal parameters, an optimal range between $-0.45 \mathrm{~V}$ and $-0.20 \mathrm{~V}$ can be found. With values inside of this range good parameter estimation is achieved, followed by high values of coherence. Inside of this voltage range the perturbation forces are fundamentally generated by the fluid film between the rotor and upper pad (under light static load conditions). The fluid film force between rotor and lower pad are kept almost unaltered. For example, if $-0.45 \mathrm{~V}$ is used with 25 bar supply pressure, the estimation of damping ratio leads to mean values around 0.12 and natural frequency around $115 \mathrm{~Hz}$, very close to the original system parameters under conventional lubrication. 
- Influence of servovalve input signal (AC Values) Analysing the influence of the $\mathrm{AC}$ values on the estimation of damping ratio and natural frequency, an optimal range between $0.2 \mathrm{~V}$ and $0.4 \mathrm{~V}$ can be found. With values inside of this range good parameter estimation is achieved, followed by high values of coherence. Inside of this voltage range the dynamic perturbation force is still fundamentally generated by the fluid film forces between the rotor and upper pad, if the DC values are inside of the range between $-0.45 \mathrm{~V}$ and $-0.2 \mathrm{~V}$.

It is worth emphasising that the information about the input signals (force and pressure) is not used for the estimation of damping ratio and natural frequency via ITD, SSI and FDD algorithms. The input signals are only used to calculate the coherence functions, to ensure the validity of claims and technically support the conclusions presented in this work.

\section{CONCLUSION \& FUTURE ASPECTS}

It is important to recall that the main goal of the work is to link active lubrication techniques with output-only modal analysis techniques to perform rotordynamic tests in a non-invasive way and bypassing any need for calibration of fluid film forces. The servovalve input signal, both DC and AC levels, and the supply pressure are the main parameters responsible for the dynamic modification of the journal pressure distribution, generating active fluid film forces. Such active fluid film forces can be used either to control, as extensively presented in the literature, or to induce rotor vibrations in a controlled manner, as investigated in the present work.

The rotor-bearing system under hybrid lubrication conditions seems to be slightly more damped than its conventionally (hydrodynamic) lubricated counterpart. Such a claim depends of course on the levels of pressurization utilized. Comparisons between the modal parameter estimations via electromagnetic shaker and ALB linked to only-output identification techniques lead to the conclusion that ALBs slightly underestimate the values of natural frequencies of the original system, especially at higher rotor angular velocities, and slightly overestimate the values of damping ratio. Such slight deviations can be strongly minimized by properly setting values of supply pressure and servovalve input signal, i.e. DC and AC levels. With the correct choice of DC voltage ranges, non-invasive perturbation forces can be generated between lightly loaded pads (upper pad) and rotor, while the behaviour of the fluid film forces between heavily loaded pads (lower pad) remains the same. It means such perturbation forces introduce minor modifications to the static equilibrium position of the journal. On top of the DC value, the $\mathrm{AC}$ value of the input signal (random or chirp) can be added and accordingly varied with the aim of shaking the rotor-level system without altering the dynamics of the original system. ITD, SSI and FDD algorithms are normally used with random signals. During the extensive experimental campaign random as well as
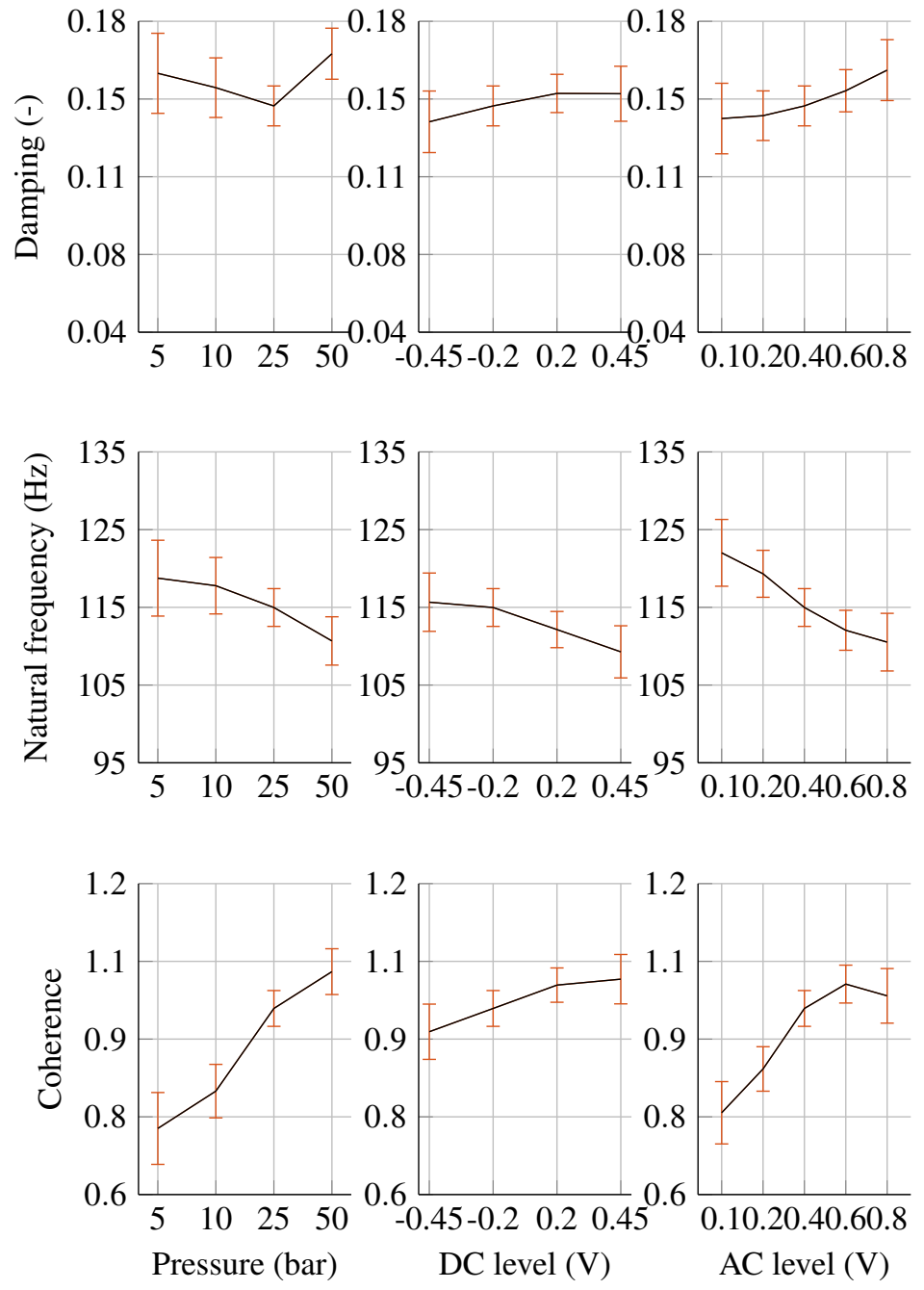

FIGURE 11: Curve-fitted mean values of damping ratio, natural frequency and coherence with $95 \%$ confidence interval as a function of: a) the supply pressure; b) DC amplitude of the servovalve input signal; and c) AC amplitude of the servovalve input signal. Dynamic perturbation: ALB as an actuator.

harmonic (chirp) signals with different $\mathrm{AC}$ levels were tested. Both types of signals used led to similar results. Nevertheless, the utilization of harmonic chirp signals instead of random signals significantly accelerates the convergence of the numerical algorithms to the correct values of damping ratios and natural frequencies, simultaneously allowing for smaller and less experimental data. One of the advantages of using electro-mechanical machine elements, such as an electromagnetic shaker and an ALB, is their versatility, allowing the utilization of all types of signals, random as well as periodic.

The implementation of ALBs as actuators in current industrial rotating machines is a relative simple task, if two sets of (piping) channels are properly manufactured to interconnect the 
machine casting, the bearing housing, and the pair of tiltingpads. This already implemented design solution is illustrated and throughout discussed in [4, p.188]. Based on such a design solution, the servovalves can be easily installed outside the machine casting, rendering the ALB systems compactness. The implementation of ALBs demands additional devices, namely: i) a high pressure pump; ii) a pair of high response servovalves; and iii) a PC-computer with a signal acquisition card and an OMA software. It is important to mention that sensing the lateral movements of the shaft via eddy-current sensors is a normal practice in many rotating machines and should not be considered as an additional device.

After the exhaustive and thorough experimental campaign one can conclude that the combination of active lubrication techniques with operational modal analysis might aid the development of novel techniques for performing rotordynamic tests in rotating machines supported by fluid film bearings. Via noninvasive fluid film forces the rotor-bearing system can be perturbed and the modal parameters of the original system accurately estimated. In the near future the novel technique will be tested using a flexible rotor [48] supported by actively-lubricated tilting-pad bearing with the aim of estimating not only natural frequency and damping ratio but also the mode shapes of the rotor-bearing system.

\section{REFERENCES}

[1] Janocha, H., 1999. "Neue Aktoren aus Sicht der Mechatronik". Kolloquium Aktoren in Mechatronischen Systemen, edited by Nordmann, $R$. and Isermann, R, FortschrittBerichte VDI, Reihe 8, Nr. 743, pp. 1-13.

[2] Janocha, H., 1999. "Adaptronics and Smart Structures Basics, Materials, Design and Applications". Springer Verlag, Berlin, Heidelberg, New York.

[3] Santos, I. F., 2011. "On the Future of Controllable FluidFilm Bearings". Mechanique et Industries, 12, pp. 275281.

[4] Santos, I. F., 2011. "Trends in Controllable Oil Film Bearings". IUTAM Bookseries, Proceedings of IUTAM Symposium on Emerging Trends in Rotor Dynamics (Springer Verlag), 1011, pp. 185-199.

[5] Santos, I. F., 1994. "Design and Evaluation of Two Types of Active Tilting Pad Journal Bearings". The Active Control of Vibration, C.R.Burrows and P.S.Keogh, eds. Mechanical Engineering Publications Limited, London, pp. 79-87.

[6] Bently, D. E., Grant, J. W., and Hanifan, P. C., 2000. “Active Controlled Hydrostatic Bearings for a New Generation of Machines”. In ASME/IGTI International Gas Turbine and Aeroengine Congress and Exhibition.

[7] Bently, D. E., Eldridge, T., Jensen, J., and Mol, P., 2001. "Externally Pressurized Bearings allow Rotor Dynamic Optimization”. VDI BERICHTE, 1640, pp. 49-62.
[8] Morosi, S., and Santos, I. F., 2011. "Active Lubrication Applied to Radial Gas Journal Bearings. Part 1: Modelling". Tribology International, 44, pp. 1949-1958.

[9] Morosi, S., and Santos, I. F., 2012. "Experimental Investigations of Active Air Bearings". IGTI/ASME Turbo Expo, pp. 1-10. GT2012-68766.

[10] Pierart, F., and Santos, I. F., 2015. "Steady state characteristics of an adjustable hybrid gas bearing - CFD, modified Reynolds equation and experimental validation". Journal of Engineering Tribology, Proc IMechE Part J, 229(7), pp. 807-822. DOI: 10.1177/1350650115570404.

[11] Deckler, D. C., Veillette, R. J., Braun, M. J., and Choy, F. K., 2000. "Simulation and Control of an Active TiltingPad Journal Bearing”. STLE Tribology Trans., 47, pp. 440458.

[12] Santos, I. F., 1993. "Aktive Kippsegmentlagerung - Theorie und Experiment, (trans: Active Tilting-Pad Journal Bearings - Theory \& Experiment)". VDI - Fortschritt Berichte, Reihe 11: Schwingungstechnik, Nr. 189, VDI verlag, Germany, p. 112.

[13] Ulbrich, H., and Althaus, J., 1989. "Actuator Design for Rotor Control". 12th Biennial ASME Conference on Vibration and Noise, Montreal, Canada, Sept.,, pp. 17-21.

[14] Cai, Z., de Queiroz, M. S., and Khonsari, M. M., 2004. "On the Active Stabilization of Tilting-Pad Journal Bearings". Journal of Sound and Vibration, 273, pp. 421-428.

[15] Krodkiewski, J. M., and Sun, L., 1998. "Modelling of Multi-Bearing Rotor System Incorporating an Active Journal Bearing". Journal of Sound and Vibration, 210(1), pp. 215-229.

[16] Sun, L., Krodkiewski, J. M., and Cen, Y., 1998. "SelfTuning Adaptive Control of Forced Vibration in Rotor Systems Using an Active Journal Bearing". Journal of Sound and Vibration, 213(1), pp. 1-14.

[17] Sun, L., and Krodkiewski, J. M., 2000. "Experimental Investigation of Dynamic Properties of an Active Journal Bearing". Journal of Sound and Vibration, 230(1), pp. 1103-1117.

[18] Osman, T. A., Nada, G. S., and Safar, Z. S., 2001. "Static and Dynamic Characteristics of Magnetised Journal Bearings Lubricated with Ferrofluid". Tribology International, 34(6), pp. 369-380.

[19] Nikolajsen, J. L., and Hoque, M. S., 1988. “An Electroviscous Damper". Proceedings of Workshop on Rotordynamic Instability Problems in High Performance Turbomachinery, NASA Conference Publication, \#3026.

[20] Goodwin, M. J., Boroomand, T., and Hooke, C. J., 1989. "Variable Impedance Hydrodynamic Journal Bearings for Controlling Flexible Rotor Vibrations". 12th Biennial ASME Conference on Vibration and Noise, pp. 261-267.

[21] Santos, I. F., and Scalabrin, A., 2003. "Control System Design for Active Lubrication with Theoretical and Exper- 
imental Examples". Journal of Engineering for Gas Turbines and Power, ASME Trans.,, 125(1), pp. 75-80.

[22] Haugaard, M. A., and Santos, I. F., 2010. "Elastohydrodynamics Applied to Active Tilting-Pad Journal Bearings". ASME Trans., Journal of Tribology, 132(2). 021702-1 to 021702-10.

[23] Theisen, L. R., Niemann, H. H., Santos, I. F., Galeazzi, R., and Blanke, M., 2016. "Modelling and identification for control of gas bearings". Mechanical Systems and Signal Processing, 7071, pp. $1150-1170$.

[24] Varela, A. C., and Santos, I. F., 2012. "Stability Analysis of an Industrial Gas Compressor Supported by Tilting-Pad Bearings Under Different Lubrication Regimes". Journal of Engineering for Gas Turbines and Power, ASME Trans.,, 134(2).

[25] Santos, I. F., Nicoletti, R., and Scalabrin, A., 2004. "Feasibility of Applying Active Lubrication to Reduce Vibration in Industrial Compressors". ASME Trans., Journal of Engineering for Gas Turbine and Power, 126(4), pp. 888-894.

[26] Santos, I. F., 1996. "Theoretical and Experimental Identification on the Stiffness and Damping Coefficients of ActiveTilting Pad Journal Bearings". Identification in Engineering Systems, M. Friswell and J. Mottershead, eds. The Cromwell Press Ltd., Swansea, Great Britain, pp. 325-334.

[27] Santos, I. F., and Watanabe, F. Y., 2004. "Compensation of Cross-Coupling Stiffness and Increase of Direct Damping in Multirecess Journal Bearings Using Active Hybrid Lubrication - Part i: Theory". ASME Trans. Journal of Tribology, 126(1), pp. 146-155.

[28] Santos, I. F., and Nicoletti, R., 1999. "THD Analysis in Tilting-Pad Journal Bearings using Multiple orifice Hybrid Lubrication”. Journal of Tribology, ASME Trans.,, 121, pp. 892-900.

[29] Santos, I. F., and Nicoletti, R., 2001. "Influence of Orifice Distribution on the Thermal and Static Properties of Hybridly Lubricated Bearings". International Journal of Solids and Structures,, 38, pp. 2069-2081.

[30] Varela, A. C., and Santos, I. F., 2012. "Performance Improvement of Tilting-Pad Journal Bearings by means of Controllable Lubrication". Mechanics and Industry, 13, pp. 17-32.

[31] Varela, A. C., and Santos, I. F., 2013. "Steady State Characteristics of a Tilting-Pad Journal Bearing with Controllable Lubrication: Comparison between Theoretical and Experimental Results". Tribology International, 58, pp. 85-97.

[32] Ulbrich, H., 1988. "New Test Techniques using Active Magnetic Bearings". Proceedings of the First International Symposium on Magnetic Bearings.

[33] Gähler, C., and Förch, P., 1994. "A Precise Magnetic Bearing Exciter for Rotordynamic Experiments". Proceedings of the Fourth International Symposium on Magnetic Bearings.
[34] Gähler, C., 1998. "Rotor Dynamic Testing and Control with Active Magnetic Bearings”. PhD Thesis, ETH Zürich.

[35] Aenis, M., Knoph, E., and Nordmann, R., 2002. "Active Magnetic Bearings for the Identification and Fault Diagnosis in Turbomachinery". Mechatronics, 12(8), pp. 10111021.

[36] Marshall, J. T., Kasarda, M. E. F., and Imlach, J., 2003. “A Multipoint Measurement Technique for the Enhancement of Force Measurement With Active Magnetic Bearings". ASME Trans., Journal of Engineering for Gas Turbine and Power, 125(1).

[37] Santos, I. F., and Varela, A. C., 2013. "Actively-Lubricated Bearings Applied as Calibrated Shakers to Aid Parameter Identification in Rotor Dynamics". IGTI/ASME Turbo Expo, pp. 1-10. paper GT2013-95674.

[38] Varela, A. C., and Santos, I. F., 2014. "Tilting-Pad Journal Bearings with Active Lubrication Applied as Calibrated Shakers: Theory and Experiment". ASME Journal of Vibration and Accoustics, 136(6). 061010, DOIs: 10.1115/1.4028452.

[39] Sichani, M. T., and Mahjoob, M. J., 2007. “Operational modal analysis applied to a horizontal washing machine: A comparative approach". presented at International Operational Modal Analysis Conference (IOMAC), Copenhagen, Denmark.

[40] Carden, P. E., and Lindblad, M., 2014. "Operational Modal Analysis of Torsional Modes in Rotating Machinery”. ASME Turbo Expo 2014: Turbine Technical Conference and Exposition, p. 9. GT2014-26305.

[41] Carden, P. E., and Morosi, S., 2014. “Operational Modal Analysis of Lateral Rotordynamic Modes of Rotating Machinery". ASME Turbo Expo 2014: Turbine Technical Conference and Exposition, p. 10. GT2014-26308.

[42] Ewins, D. J. Modal Testing: Theory, Practice and Application. Wiley.

[43] Ibrahim, S. R., and Mikulcik, E. C., 1977. "A method for the direct identification of vibration parameters from the free response". The Shock and Vibration Inform. Ctr. Shock and Vibration Bull. Part. 4, pp. 183-198.

[44] Juang, J.-N., and Pappa, R. S., 1985. “An eigensystem realization algorithm for modal parameter identification and model reduction". Journal of guidance, control, and $d y$ namics, 8(5), pp. 620-627.

[45] van Overschee, P., and de Moor, B., 1996. Subspace identification for linear systems. Theory, implementation, applications. Kluwer.

[46] Brincker, R., Zhang, L., and Andersen, P., 2000. "Modal Identification from Ambient Responses Using Frequency Domain Decomposition". Proceedings of Spie.

[47] SAS Institute Inc., 2015. SAS/STAT software, version 12.1.0.

[48] Salazar, J. G., and Santos, I. F., 2015. "Feedback- 
Controlled Lubrication for Reducing the Lateral Vibration of Flexible Rotors Supported by Tilting-Pad Journal Bearings". Journal of Engineering Tribology, Proc IMechE Part J, 229(10), pp. 1264-1275. DOI: $10.1177 / 1350650115577027$. 